\title{
STEM NETWEAVER DIALOGUES: CREATING, DESIGNING, AND MANAGING TRANSFORMATIVE NETWORKS
}

RESEARCH TEAM LEADER:

BRUCE EVAN GOLDSTEIN, ASSOCIATE PROFESSOR, PROGRAM IN ENVIROMENTAL DESIGN, UNIVERSITY OF COLORADO BOULDER

RESEARCH TEAM MEMBERS:

LISA SMITH, INDEPENDENT CONSULTANT

MELANIE RYAN, INDEPENDENT CONSULTANT

A REPORT FROM THE NETWORK OF STEM EDUCATION CENTERS,

HTTP://SERC.CARLETON.EDU/STEMEDCENTERS/INDEX.HTML.

University of Colorado Boulder

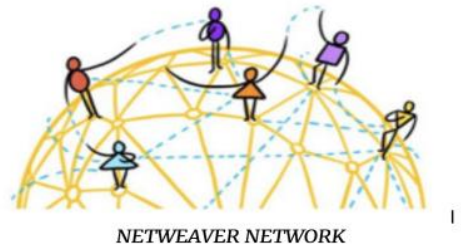

NETWEAVER NETWORK 
STEM Netweaver Dialogues: Creating, Designing, and Managing Transformative Networks

\section{ACKNOWLEDGMENTS}

This material is based on work supported by the National Science Foundation under Grant No. (1524832). Any opinions, findings, and conclusions or recommendations expressed in this material are those of the authors and do not necessarily reflect the views of the National Science Foundation.

\section{CONTENTS}

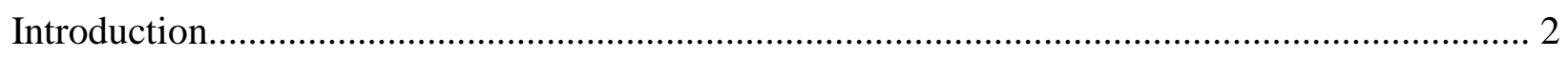

Summary

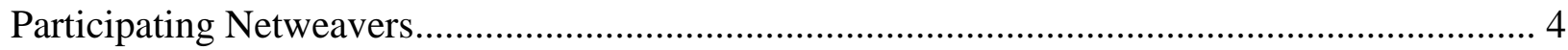

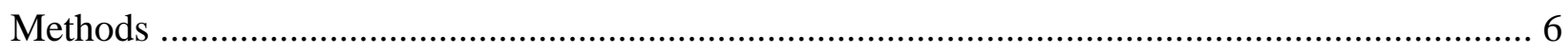

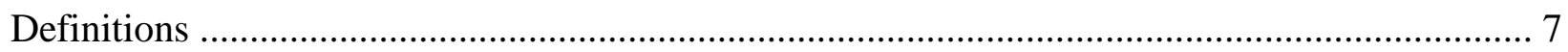

Dialogue 1: Maintaining Connection for Transformation.......................................................... 8

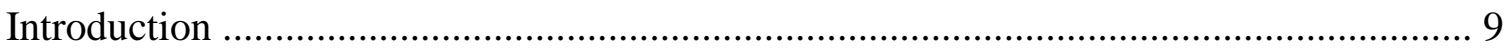

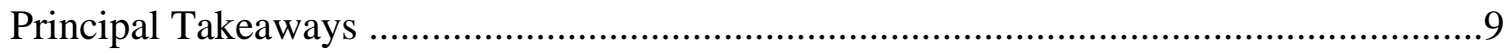

Dialogue 2: Transformative Assessment............................................................................ 12

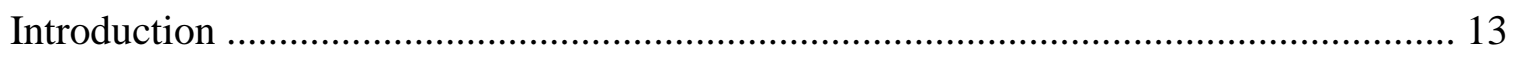

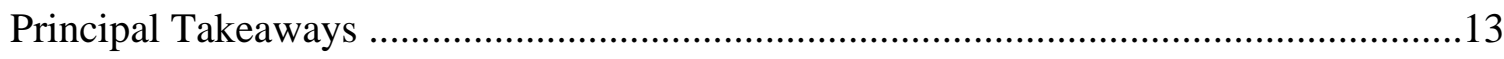

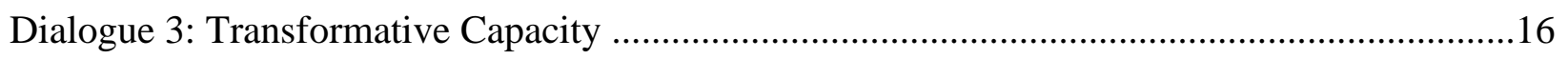

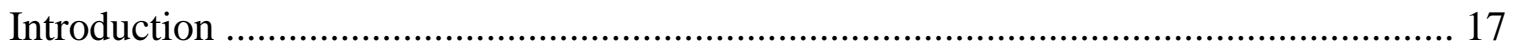

Principal Takeaways ……………………………………...................................18 


\section{INTRODUCTION}

The Network of Stem Education Centers (NSEC) is an organization of campus-based STEM (Science, Technology, Engineering and Math) centers and offices that serves as a catalyst for broader national educational transformation in STEM. This includes research on teaching and learning STEM disciplines at all levels. NSEC works with other STEM Networks to enhance collective capacity by identifying effective network design and facilitation strategies.

During the last half of 2019, NSEC convened three 90-minute network learning dialogues with four leading experts in network facilitation, systems change, and STEM education reform. The focus was on designing, creating, facilitating, and managing transformative STEM learning networks.

The topics were:

- Maintaining Connection for Transformation

- Transformative Assessment, and

- Transformative Capacity Building

\section{SUMMARY}

The principal themes of each dialogue were:

\section{1: Maintaining Connection for Transformation}

The importance and challenges of maintaining virtual connections supporting face-to-face community. The need to control for emergence was underscored, as was the transition of values and identities through emergence and transformation. Finally, participants emphasized the role of netweavers in serving as both pathfinders and gatekeepers.

\section{2: Transformative Assessment}

Th need to accept emergence and surprise in pursuit of transformation, and the inherent conflict of valuing those ideals while seeking to assess progress toward transformation. The tension between permanence and dissolution, as well as the porous and variable nature of a transforming network, impacts the ability to measure and evaluate the transformation. Appropriate standards of valuation may not yet have developed that can appropriately assess transformation capacity. Successful transformation means that systemic change becomes part of the fabric of the network, and therefore becomes embedded and invisible. As this implies, providing quantitative or qualitative measurements of change to funders, participants and others is an ongoing challenge. 


\section{3: Transformative Capacity}

Emphasis on the interplay between islands and network, loneliness, and support. Networkwide resilience is tied to individual resilience. Overall progress may be helped by sometimes counterintuitively deliberately slow movement versus valuing perceived speed toward transformation. It is important for participants to be supportive of and ready for transformation. At times, an immovable obstacle to transformation may easily and unexpectedly give way. 


\section{PARTICIPATING NETWEAVERS}

The STEM netweavers who participated in the dialogues were:

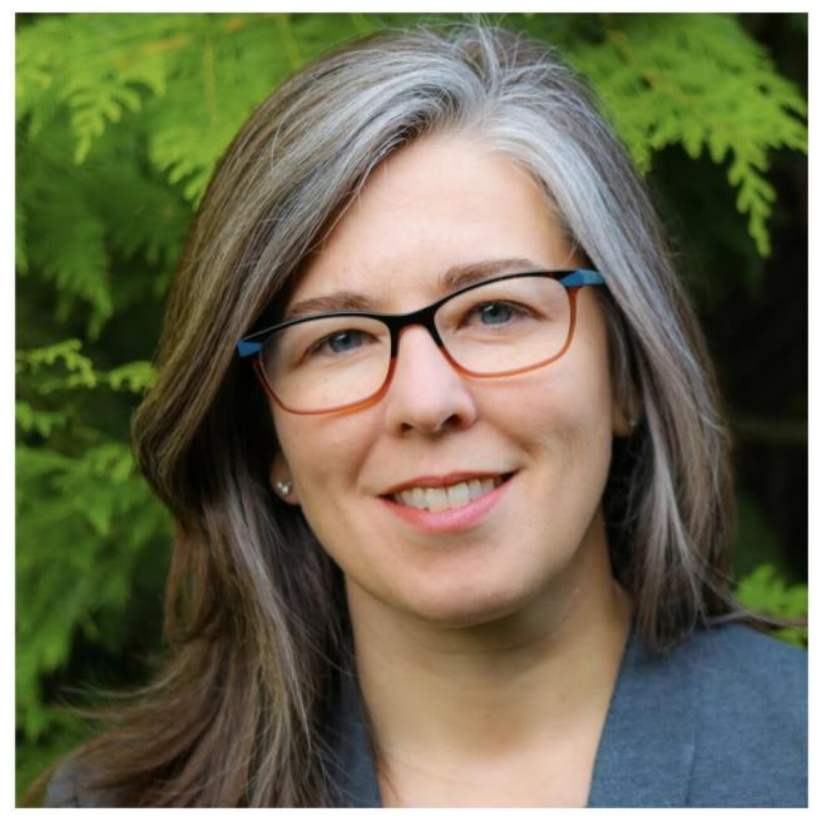

Julie Risien

Associate Director, Oregon State University's Center for Research on Lifelong STEM Learning

Julie is the Associate Director at Oregon State University's STEM Research Center. She leads the Center's research and programmatic portfolio on improving connections at the interface of society and science. She researches the transformative power of learning networks, organizational structures, professional growth, academic systems of reward and incentives, and partnerships. Julie leads the scholarship initiative for Advancing Research Impacts in Society and manages the Inclusive Excellence @OSU initiative aimed at transforming undergraduate education. She serves on the steering committees for the National Alliance for Broader Impacts (NABI) and Undergraduate Field Experiences Research Network (UFERN) and is graduate faculty in both Earth, Ocean and Atmospheric Sciences and Environmental Sciences.

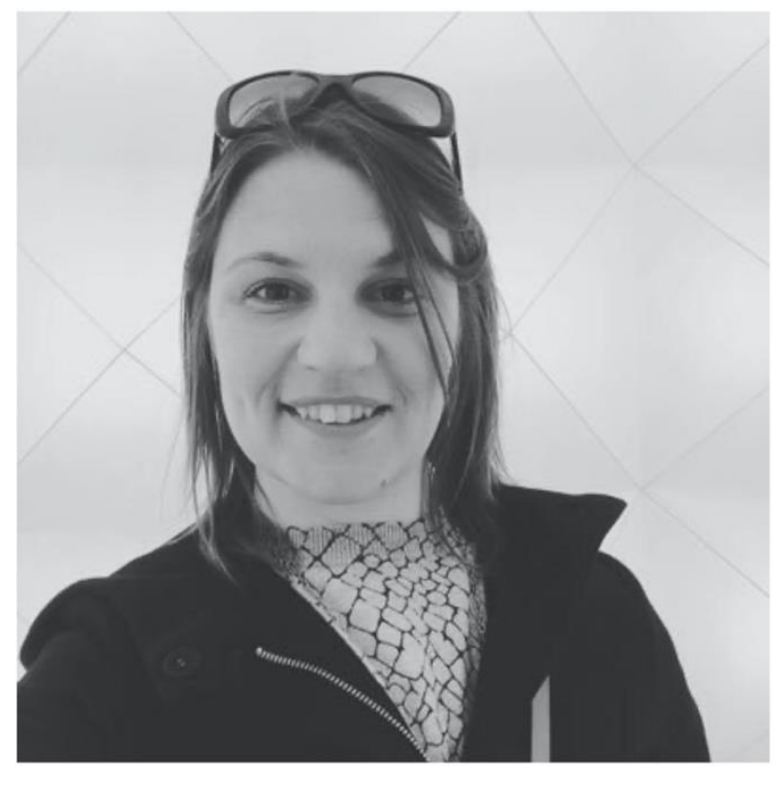

Lou Woodley

Center Director, Center for Scientific Collaboration and Community Engagement (CSCCE)

Lou is Director of the CSCCE - a research and training center which serves to study, champion, and train scientific community managers. Lou is a trained molecular biologist with research experience at Cambridge University, the European Molecular Biology Laboratory in Heidelberg, and the Centre for Genomic Regulation in Barcelona. Prior to her current role, Lou spent 5 years at AAAS, building and studying Trellis, an online 
communication and collaboration platform for scientists. Earlier in her career, Lou spent 5 years overseeing Nature Publishing Group's community projects often working at the intersection of scientists and new technologies. She has also organized community-focused events of various formats and sizes, many of which have focused on science communication and the future of scholarly

communications.

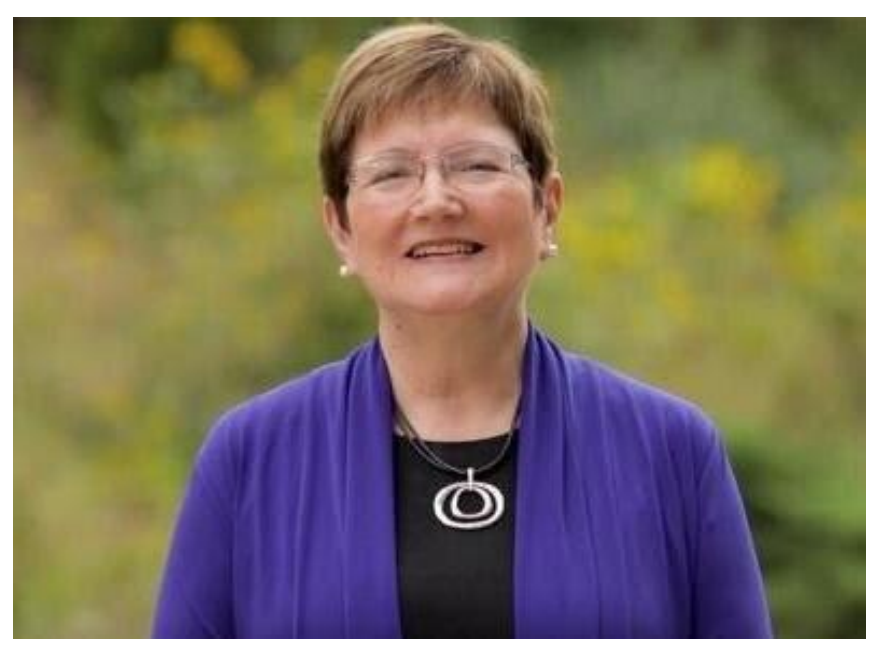

\section{Ann Austin}

Professor of Higher, Adult, and Lifelong Education, Michigan State University

Ann is a Professor of Higher, Adult, and Lifelong Education at Michigan State University, where she was selected as the Mildred B. Erickson Distinguished Chair in Higher, Adult, and Lifelong Education. She also is currently serving as a Program Director in the Division of Undergraduate Education at the National Science Foundation in Washington, D.C. Her research concerns faculty careers and professional development, organizational change in higher education, the academic workplace, teaching and learning in higher education, doctoral education, reform in science, engineering, and mathematics (STEM) education, and equity and inclusion in academe.

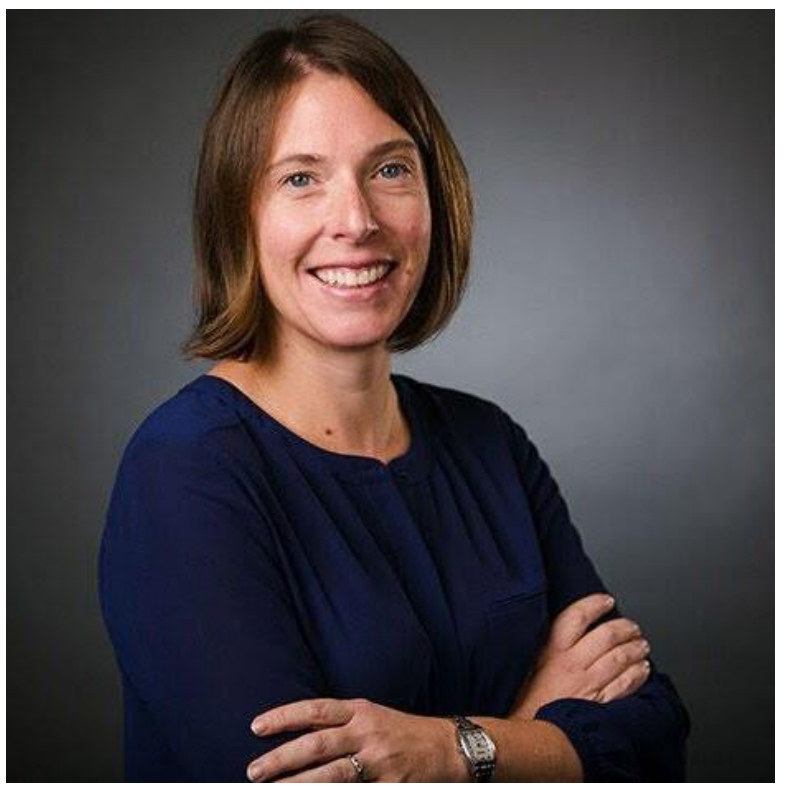

Emily Miller

Associate Vice President for

Policy, Association of American

Universities

Emily, as the Associate Vice President for Policy for AAU, has primary responsibilities for collaborating with member campuses on institutional policy efforts related to undergraduate and graduate education. She directs the AAU Undergrad STEM Education Initiative and the $\mathrm{PhD}$ education initiative. She also staffs AAU's STEM Network and Association of Graduate Schools constituent groups and serves as liaison to the AAU Arts \& Science Deans group. Emily was a research and curriculum specialist for the 
Association for Community College Trustees, an assistant director of career services at Tufts University, worked in alumni relations at Harvard Business School, and collaborated with the Association of Governing Boards.

\section{METHODS}

The insights presented here were principally derived from three 90-minute online dialogues convened on Zoom on July 22, 2019, August 29, 2019, and September 18, 2019. In each of these dialogues highly experienced netweavers discussed the challenges of building and maintaining change-making networks. The results of these dialogues were initially captured by visual scribe Emma Ruffin, and then analyzed to identify insights to support a STEM netweaving community of practice.

Participants in each dialogue were sent follow-up questions to stimulate additional ideas and reflection. The dialogues were recorded and transcribed, and the transcription and responses to follow-up questions were coded and analyzed using Delve content analysis software. Analysis of individual cases was guided by grounded theory with an emphasis on identifying emergent themes and insights. This report contains the principal ideas from this analysis, along with direct quotations from the participating netweavers, which were edited to enhance their clarity and enable them to stand alone in this format. These edits were limited to changing tense or pronoun and removing elements characteristic of verbal speech (e.g., phrases like "um" and "well"). 


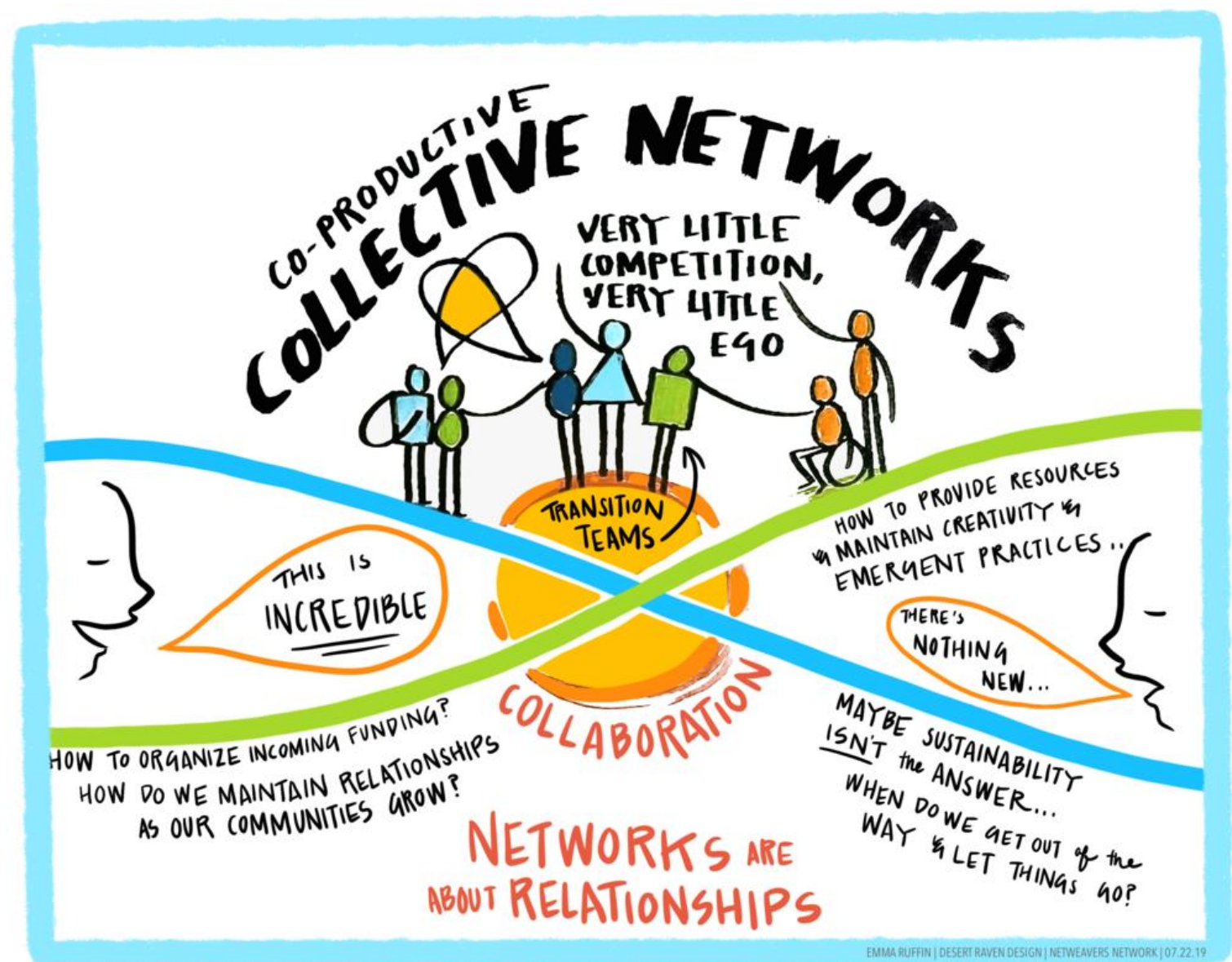

Image by Emma Ruffin

\section{Definitions}

Learning networks bring together practitioners to promote place-based learning and system-wide adaptation in response to pressing social and ecological challenges. This creates a dynamic environment through which innovation can flow and shared capacity can grow whether the focus is reef resilience, urban sustainability, ecological fire restoration, or food security.

Transformative learning networks amplify the potential for transformative change by disrupting old habits, fostering new relationships, and providing communities with the freedom to define their own place and purpose while promoting collective action at higher organizational scales. Transformative learning networks can be powerful engines for change - and they take special skill and attention to create and maintain. Learning networks rely on skilled network facilitators, or "netweavers".

Netweavers support the health of a network by enabling the flow of ideas, building strong ties that facilitate information flow, and forging a common voice to promote systems change. Netweavers knit their networks together to develop collective capacity to overcome resistance to systems change. 
Dialogue 1: Maintaining Connection for Transformation (Sweat the Small Stuff) - Convened July 22, 2019

\section{SWEAT the SMALL STUFF}

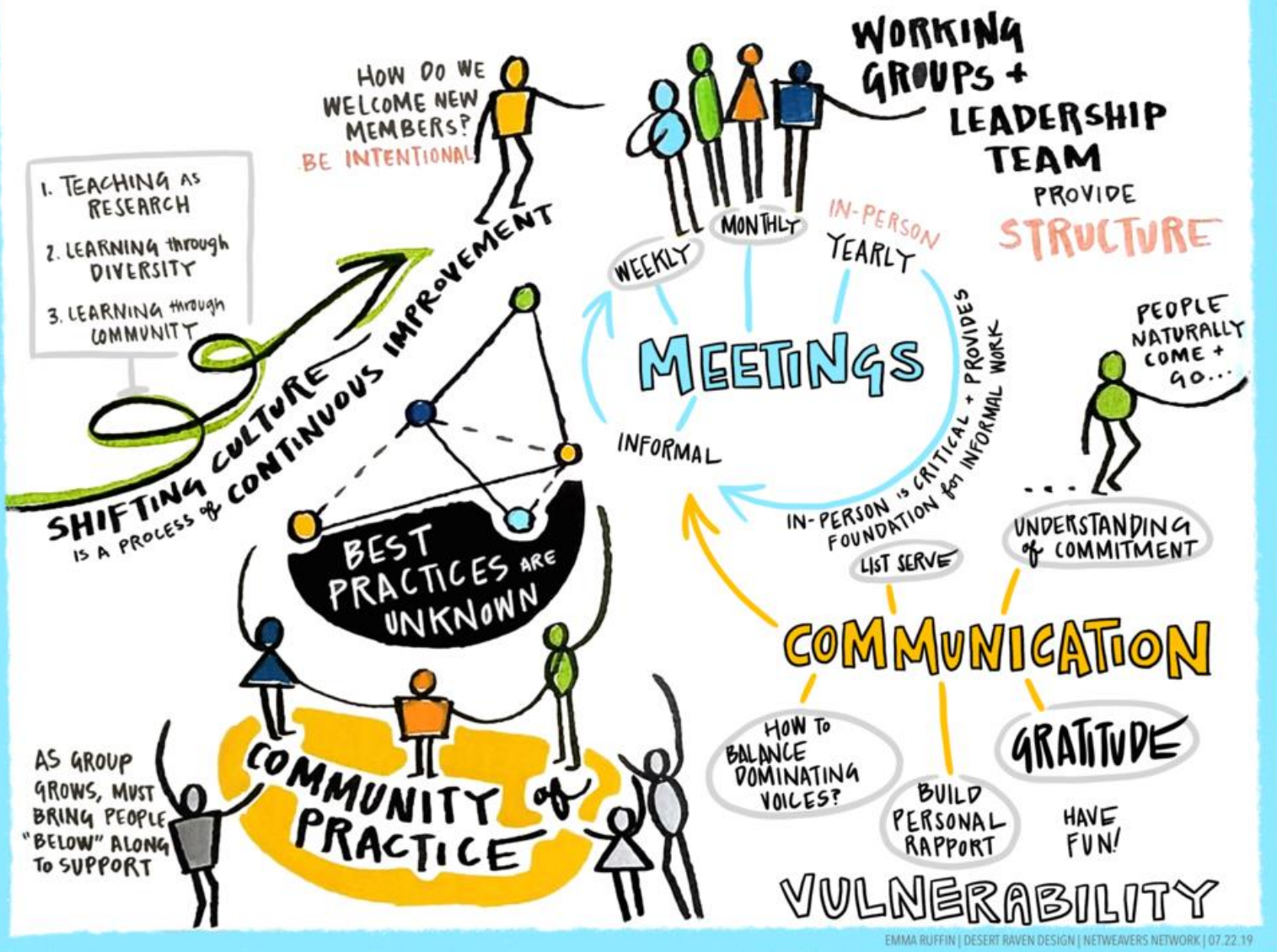

Image by Emma Ruffin

Facilitators:

- Melanie Ryan, Independent Consultant/Netweaver Network

- Emma Ruffin, Desert Raven Design/Netweaver Network (Visual scribe)

Netweavers:

- Julie Risien, Associate Director at Oregon State University's Center for Research on Lifelong STEM Learning

- Ann Austin, associate dean for research and a University Distinguished Professor at Michigan State University

- Emily Miller, Director of AAU Undergraduate STEM Education Initiative 
Emily participated in the dialogue for the first 40 minutes of the call.

\section{Introduction}

The Sweat the Small Stuff (Maintaining Connection for Transformation) dialogue was organized to explore how netweavers facilitate ongoing connection in networks in between in-person convenings. We know that effective organizers can create strong ties that help align activists around a collective goal. This occurs through sustained personal interaction, as activists develop relationships and see their commitment matched by the commitment of others. Annual network meetings, learning exchanges and trainings can help with this network process. However, in between big, expensive, and logistically complex events, members may be isolated from the larger network. Thus, a challenge netweavers share is harnessing this collective energy in the absence of ongoing personal contact.

The conversation was framed around the following questions:

- How do you engage network members to create and sustain deep connection?

- How easy or hard is it to maintain informal connections?

- When events become routine, do you find you see the same faces every year?

- Are connections a result of familiarity and existing relationships? Because of activities you offer members when they are apart?

- How do you identify and track what sustains deep connection?

-What is at the root of achieving deeper commitments from your members?

- What do you want to see more of in your networks and in your work in this area?

○ How does that desire compare with the netweaving that you currently do?

- What would have to change? What would be the cost?

- Do you think early phases of network formation attract a different kind of activist and engagement?

\section{Principal Takeaways}

\section{Virtual connections can be cultivated in ways that yield the benefits of face-to-face community}

The netweavers discussed how to connect their networks in ways that foster the relationships and interpersonal skills usually associated with face-to-face connection, such as empathy and patience. Further, they noted that cultivating people's potential to participate effectively in virtual community has the additional benefit of helping them be more effective online educators, which is increasingly the trend - even before Covid-19.

\section{Control for emergence}


The netweavers agreed that in the early days of their networks what drew people together was an informal sense of shared purpose and culture:

"There's an undercurrent of a common ethic and heritage about what we're actually trying to do. And I would say, also kind of an underdog culture a little bit, a sense that we're in it together." - Julie Risien

Over time, this strong sense of mutual purpose and culture may shift:

"How to maintain the relationships as you grow is a very interesting challenge.... And I think it relates to what you were saying...when smaller, you're all interacting together, as it gets bigger, that doesn't happen as easily. And so, the very things that have produced the energy, the relationships are more challenging to maintain." - Ann Austin

The netweavers discussed two initiatives, one spanning a few years and the other almost two decades. In the longer initiative, conscious efforts were made to steer emergence, rather than having it arise in a purely organic way. The netweavers concluded by asking some questions about whether it is possible to deliberately steer the community to achieve emergent relational features and reflected on whether there is a difference between emergence that is "organic" vs. that which is anticipated and facilitated. Is it possible to know whether there a need to plan in this way versus allowing relationships to arise organically? Should netweavers learn to trust that structure will yield the appropriate agency?

"The structure and the way of staying in contact are very related to each other - there must be very careful attention to the structure that enables people to be in contact" - Ann Austin

3. Energy in systems for transformation: Values that inspire later become values to release: a shift from intrinsic values to instrumental values in order to serve a wider network

The netweavers reflected on what created capacity for system transformation. They observed that in a network's early days the key factor was the energy invested by those setting up the network the netweavers. Then, as networks scale, there is an injection of energy in the form of money, infrastructure, etc. The energy directed toward transformation and learning shifts from the 'soft' resources of human action and becomes 'hard' organizational resources. They linked this back to the earlier 'control for emergence' theme - initial netweaver commitment is critical, but matters less as scale is achieved:

The netweavers noted that those who join the network later may do so because of instrumental values rather than intrinsic values. Initially people may feel intrinsic motivation centered on values and identity that drive creation of the network and netweaving. As networks move to a more external and wider serving function, alignment with early values and identity may change. Therefore, not every member of the early network may remain engaged as the energy in the system shifts: 
"One phenomenon that we've had, as we've grown, is that the people who are invested early on, they're wanting the conversation to be deeper, more sophisticated, more forward looking. You've got the people who are first attracted to it. And as more [people]...come to the side, the whole thing eventually kind of collapses.

"One of the things we've had...at our annual meeting...this is sort of conference-style summit. We're hearing from people who've been involved for a long time, 'There's nothing new, there's nothing new.' And then we're hearing from people who come for the first or second time that, 'This meeting is rocking my world, I finally found my people, God, I can't believe I've been missing you all this time.'

"There's a real difference in expectation and needs based on longevity. We struggle with how to have that deeper and more sophisticated experience, while still being really welcoming and growing the community and providing new professionals what they need, or professionals who are just kind of exploring a new space." - Julie Risien

\section{Two types of network power: soft and hard}

The netweavers compared the "soft power" for changemaking from inter-organizational networks to the "hard power" within their home campuses and organizations. They noted that ego and power-based relationships within their home networks could constrain changemaking, whereas inter-organizational networks tended to have fewer power hierarchies and support a bigger picture view:

"What's amazing about this network of people that cuts across all these different networks, is that there's very little competition. I mean, people sometimes are applying for the same grant opportunities and things like that. But there's an amazing openness to sharing ideas [and] supporting each other... People will say, oh, who wants to be the lead on this, it's not like people are vying for it, it's whoever is the right person, has the time, people are handing off, it's like a ball...you're playing a game or just tossing to this person, because they have a little time, toss it to the next person, very little ego in this, which is really quite amazing." - Ann Austin

However, the dialogue participants also discussed how the soft power of the network could at times be transformed into hard power as participants accessed capacities that were inaccessible within their home networks. They observed that network participants could subvert hard power relationships by deploying the network's soft power, while also noting a paradoxical widespread belief that hard power was more effective, which could lead netweavers to believe that they had a moral imperative to employ hard power, despite actually preferring to cultivate soft power. 


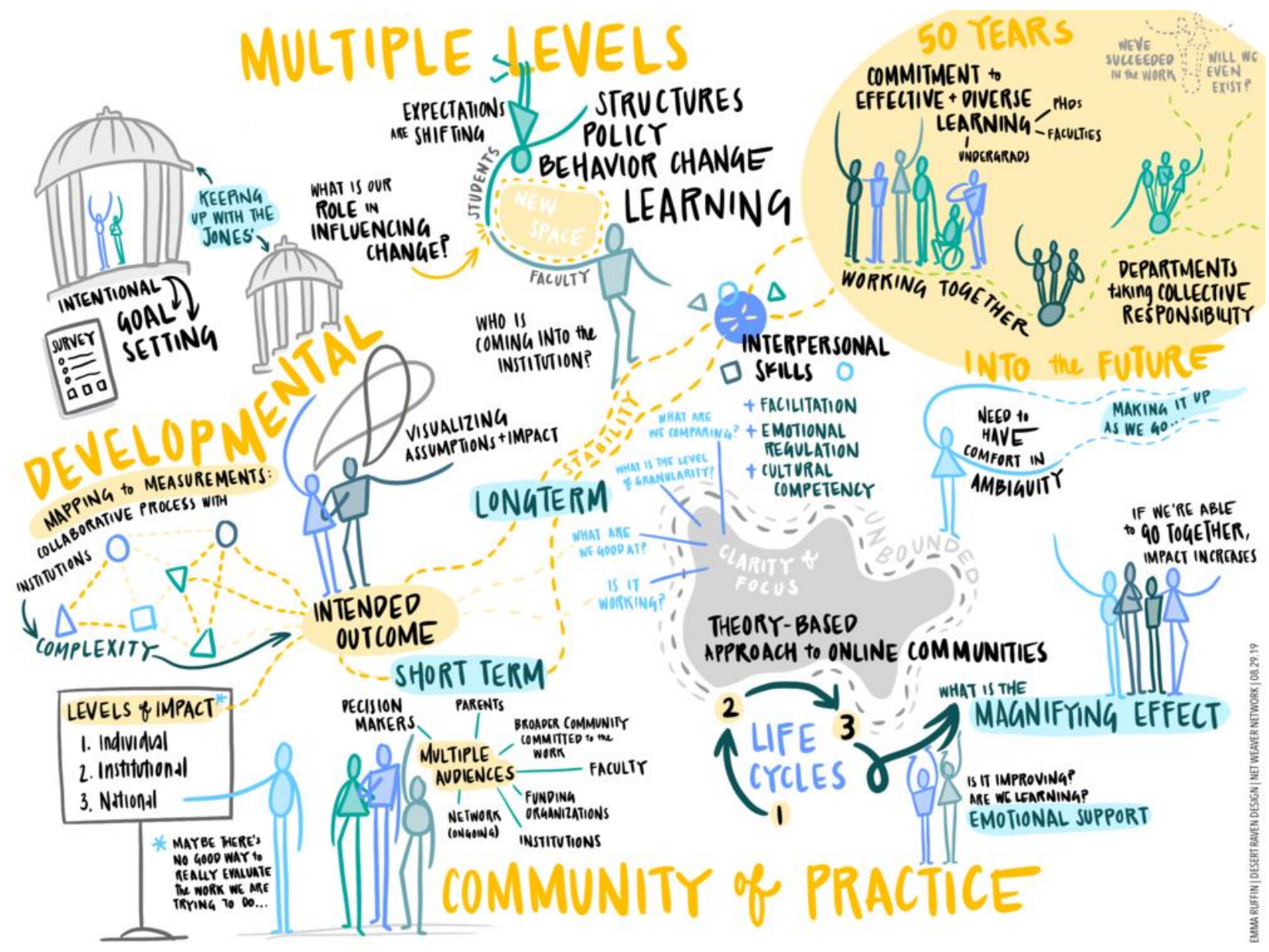

Image by Emma Ruffin

Facilitators:

- Melanie Ryan, Independent Consultant/Netweaver Network

- Emma Ruffin, Desert Raven Design/Netweaver Network (Visual scribe)

Netweavers:

- Julie Risien, Associate Director at Oregon State University's Center for Research on Lifelong STEM Learning

- Ann Austin, associate dean for research and a University Distinguished Professor at Michigan State University

- Emily Miller, Director of AAU Undergraduate STEM Education Initiative. 
- Lou Woodley, Center Director, Center for Scientific Collaboration and Community Engagement (CSCCE)

\section{Introduction}

How do choices and action lead to change, and does netweaving make a difference? Network members want to understand what they have accomplished together, particularly whether they have had an impact on the system(s) they seek to change. Funders are also interested in whether their investment is well-spent, and how and where to keep investing. But understanding the impact of netweaving is challenging. There are many potential levels of impact - at the individual level of the network member, at the collective level of the landscape or community, at the network level and at the institutional, whole-system level. Further, impacts vary across the system, not all of them transformative and at many scales. And different kinds of evidence of change are powerful to different audiences. Finally, different assessments serve different purposes.

The conversation was framed around the following questions:

- How do you monitor how your network is moving toward your stated outcome?

- What transformative assessment techniques have worked?

- Who needs to know about your progress - what audiences?

-What would you like to be able to assess?

- If you had enough time and resources to do transformative assessment "right", what would that look like?

- How has your assessment work made a difference? Has it provided effective guidance or enhanced support for your networks?

- What are you taking from this conversation about how assessment can or cannot support your network's capacity to transform the larger system in which it is embedded?

- Given that transformation is often unpredictable and there is no precedent for the new future, how should netweavers evaluate what has not been done before?

\section{Principal Takeaways}

1. Network durability and obsolescence: Having impact may make the network unnecessary

The netweavers noted that networks are not intended to be permanent institutions, and that the most successful network might actually be the one that vanishes without a trace. 
"You might never know our network existed. It might have done enough and been part of a systemic transformation that you would only read about it in the history of science literature. I'm thinking that means that the profession has done its job and become obsolete because our education system now works to integrate research and society much more effectively." - Julie Risien

2. How do you measure emergent and transformative changemaking capacity?

The netweavers discussed the challenges of trying to identify static measures for evaluation when their networks were operating at multiple scales, were necessarily porous without clear boundaries delineating "insiders" and "outsiders" and were always in flux. Additionally, the risk in making something available to evaluation is that in making the network stable enough to be measured you may cut out a critical feature of an effective network - its dynamism and lability, and even its capacity to do two or more things at once to meet the needs of different participants.

"Data is really important, because it helps us scale on lots of different levels, to go to funders to get our work continued, to collaborate and grow together. But what is the appropriate level of granularity? We can have data, but we need to contextualize it for the people we're sharing the data with, and that in and of itself can be a lot of work.

It's not just that we're struggling with what we measure. Are we comparing apples with apples and designing this well? Numbers are not always enough - there's an emotional component that we find. It's really hard to manage and identify. And when we do have something we've captured, communicating that to various different audiences is a big challenge too." - Lou Woodley

3. Different kinds of evaluation for different, and sometimes overlapping, purposes

Network evaluation is not only often a requirement of funders and sponsors, but also a critical component of ongoing course adjustment, which is often called developmental (as opposed to summative and formative) assessment.

"A primary audience has been the network itself - everything we learn is fed right back into the network to make adjustments and improve how the network works at local sites and across the broad network." - Ann Austin

The netweavers discussed how they had performed a variety of evaluations and collected different types of data across different scales - individual, collective, and network-wide. With so many possible questions to ask, wherever possible, they sought to use the same data to ask different questions to address the questions of different audiences. 
"Funding organizations have somewhat different expectations, and we've had to have explicit data reports and annual data collection that's very consistent, very systematic. Some of the foundations wanted data about participation, about program outcomes.

Another audience for evaluation that is a little fuzzier is national audience of the community of people who are committed to reform and excellence in undergraduate and doctoral education..." - Ann Austin

Evaluation methods they had used included:

- Institutional portraits

- Interviews

- Case studies

- Systematic and multi-methodologies approaches

- Employing an external evaluator

- Longitudinal monitoring of cohorts

- Tracking skill sets

- Tracking evolution of communities versus theoretical phases

- Theory-based approach to transformation

4. Evaluation data demonstrating effectiveness is not the only way to propagate change

The netweavers noted that some organizations adopted transformative behavior because another peer or competitor organization was also pursuing it - which can be thought of as a positive contagion effect, peer pressure, or "keeping up with the Jones'." They concluded that it is important to match your evidence to what will motivate your target.

5. Paradoxically, qualitative data is considered weak evidence, even when the changes sought are themselves qualitative

In challenging the low value assigned to qualitative data versus other forms of data, the netweavers noted that quantitative data is often ill-suited to measuring transformation. The netweavers also acknowledged the irony that, since networks pursue transformation, they are oriented toward emergence, synergy and surprise, yet when evaluating progress towards transformation, a linear and incremental paradigm is applied. 


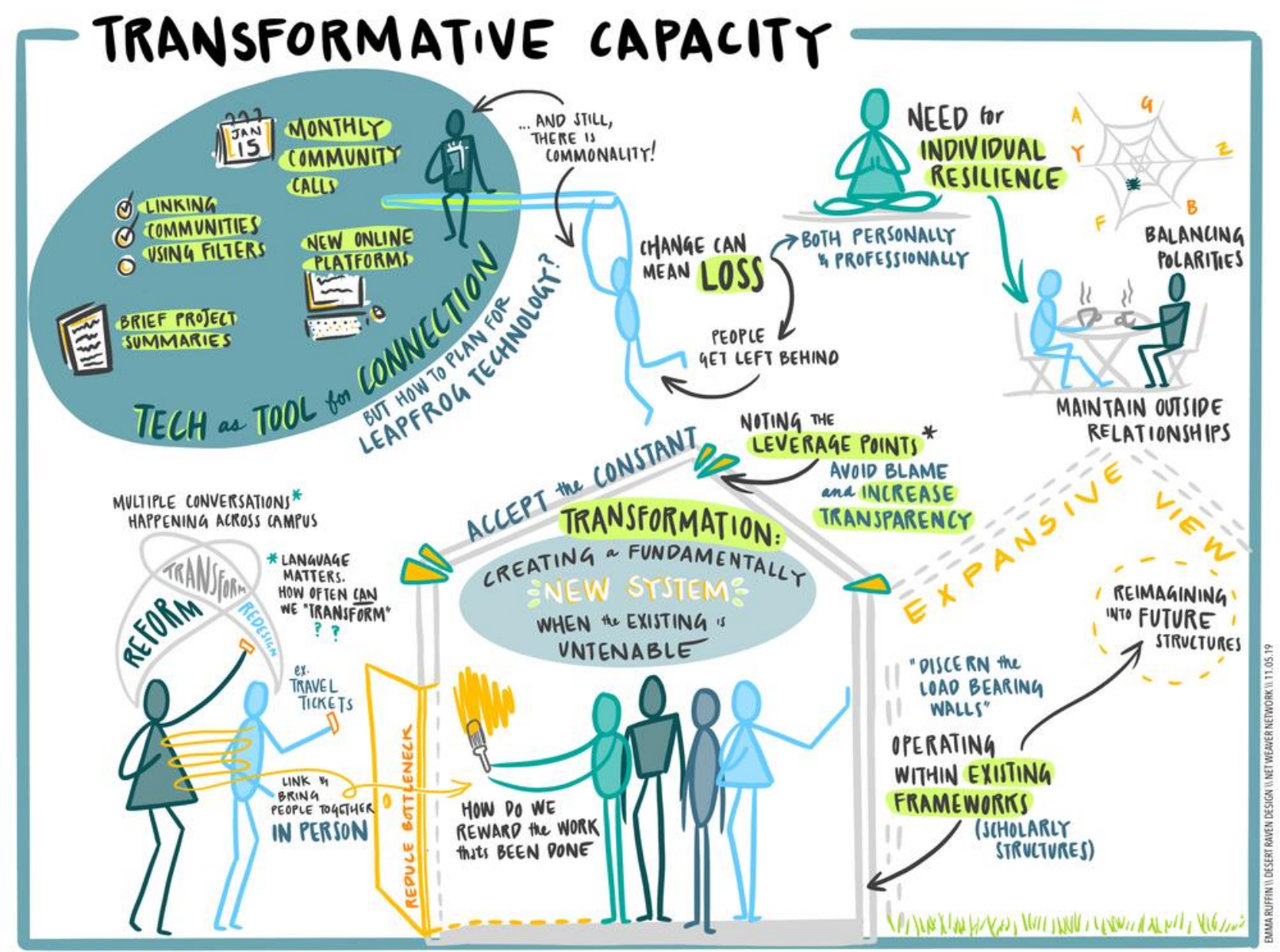

Image by Emma Ruffin

Facilitators:

- Melanie Ryan, Independent Consultant/Netweaver Network

- Emma Ruffin, Desert Raven Design/Netweaver Network (Visual scribe)

Netweavers:

- Emily Miller, Director of AAU Undergraduate STEM Education Initiative

- Lou Woodley, Center Director, Center for Scientific Collaboration and Community Engagement (CSCCE) 


\section{Introduction}

This prototype was organized around the theme of transformative capacity. The quote "Transformative capacity is the ability to create a fundamentally new system when ecological, economic, or social (including political) conditions make the existing system untenable" was used as a prompt for reflection. The netweavers explored questions related to capacity building and what it means for a network to develop such capacity, such as "How can netweavers recognize transformative capacity when they see it, and how can they cultivate it?"

The conversation was framed around these questions:

- If a new and viable alternative to the existing system is the goal, how do netweavers build capacity for such a change?

- Sometimes transformative capacity requires a long-term approach. Can you reflect on a moment in time when you could not enact a change, but years later could change things because you had changed the system?

- What made that transformation effective and efficient?

- How did time play into transformative capacity?

○ How did openness emerge in the system? Was there latent capacity?

- What have you seen work and not work when designing, organizing, and facilitating network learning?

- Are there specific ways you have encouraged people to learn together about transformation and capacity?

- Is there a need to negotiate a consensus? Have you seen competition around different goals for transformation?

- Must transformation be organic? Can you do structured work to help it along?

- One idea is that there is a "stewarding phase" in which netweavers strengthen knowledge and self-organization and then unlock, reveal, and break down existing structures in order to facilitate transformational change.

- In your experience, does change happen in a predictable way?

$\circ \quad$ Or is it a different sequence every time?

- Do you begin stewarding and then transform or vice versa?

- Is there an assumption that everyone needs to move to the new, transformative path or there is an acceptance that some people will not?

- What are your strategies for managing winners and losers created by transformation? Have you seen strategies that allowed for both loss and positive impact? 
- How do you support people in your network who are disliked or seen as the "bad guy" for pursuing transformative change?

- How can network members be resilient, adaptive, calm, and open to change?

- How does a network of people take on the load of transformative change collectively?

- Does it typically fall to one individual to take the leadership role or have you seen people structure group roles together?

\section{Principal Takeaways}

\section{Go deep}

The netweavers asserted that effective netweaving required knowing where, when, who and why capacity exists for transformative change. Uncovering this capacity involves provoking members to ask deep questions about underlying paradigms and institutional philosophy, considering structural constraints on change, and bringing personal questions about fear of loss as well as risk and control to the center of the conversation.

\section{Focus on personal resiliency}

The netweavers observed that maintaining connectedness and a sense of wholeness require careful attention so that individuals can remain resilient while they consider and engage with transformative alternatives. Paradoxically, transformative capacity may be closely tied to resilience. Resilience capabilities include learning to live with change and uncertainty, nurturing system diversity, enhancing memory for system renewal, combining different types of knowledge for learning, and creating opportunity for self-organization and flexible problem solving across scales.

\section{Go slow to go fast}

Speed and velocity dance with each other - sometimes the perception of going nowhere (certainly not forward) is actually the best way to go faster later on. Sometimes the person steering the transformation needs to let others wait until they are ready. The netweavers noted that taking chances with transformative arrangements bears risks that if gotten wrong, can result in stagnation and stress, encouraging people to return to a non-functional status quo simply because it is familiar. The question thus is when to hold still and strong in order to allow transformation to unfold.

The netweavers suggested that transformative capacity was multi-scalar, spanning changes at the individual, organizational and whole-network scales. Some degree of stability at one scale may be necessary in order to let go and disrupt systems at another - netweavers can help balance change and loss with control and stability and through a transformation process. 